\title{
Inventory Information System using Technique of Data Mining Companies Warehousing
}

\author{
Raden Adhiyaksa Indiharto, Atiqah Meutia Hilda \\ Informatics Study Program, \\ Faculty of Engineering \\ University of Muhammadiyah Prof. DR. Hamka \\ radenadhiyaksa89@gmail.com, \\ atiqahmeutiahilda@gmail.com
}

\author{
Fitri Mintars ih \\ Informatics Engineering Study Program, \\ The Faculty Of Science and Technology of \\ UIN Syarif Hidayatullah Jakarta \\ South Tangerang - Banten \\ fitri.mintarsih@gmail.com
}

Diterima: 11 September 2016. Disetujui: 25 Oktober 2016. Dipublikasikan: Nope mber 2016

\begin{abstract}
The mechanism of procurement of goods that were done manually, but now it can be facilitated by the existence of web-based procurement system. This system is designed using the data mining technique to find any parts of the goods data that often requested based on a monthly period/year and knowing the type of goods are the most requested and the most frequently consumed the preparation. This research uses a decision tree method and CARTS (Classifcation and Regression Tree) algorithm for exploring the data. The design method of this system using object-oriented development with UML modeling system. Inventory information system software is used to facilitate the process of procurement of goods and the existing equipment on the warehousing company multi-user web-based by the mechanisms of the process of the administration and procurement of goods made online. This application is supporting the administration process of procurement of goods in each company warehouse. This application is equipped with features to request the procurement of goods, maintenance procurement of goods and procurement of goods online report. The purpose of this research is to produce a web-based inventory information system that make easier and speed up the process of inventory and procurement of goods in a company warehouse.
\end{abstract}

Keywords : inventory, data mining, algorithm carts, warehouse, web.

\section{INTRODUCTION}

Each job has a level of complexity that vary more complex workflow work, then the more complex the system is, that will be made to complete the work. One of them is the process of the administration of the procurement of goods. From the request in the procurement of goods, maintenance procurement of goods, until the reporting of procurement of goods. It can be resolved with both without even obstacles. But when the procurement of goods is more and more complex, the user will have difficulty in the conduct of the administration of the procure ment of goods.

Based on this condition, this research focus on create an information system that will solve all the problems faced by the user. This application aims to help users to request the procurement of goods, maintenance procurement of goods and reporting procurement of goods. The system will provide early detection report of the ability of the goods in the warehouse. Otherwise the decision maker can decide and immediately instructed to avoid the void of goods in the warehouse.

This system use data mining techniques with the decission tree modeling system based on the CARTS (Classification and Regression Tree) algorithm. The development method of this system is using UML method (Unified Modeling Language) that can help simplify and speed up the process of the preparation and procurement of goods on the part of logistics/warehouse.

\section{LITERATURE REVIEW}

\section{A. Preparation (Inventory)}

In the general sense of the preparation goods is implementing activities dealing, organizing, settings, records and goods registration inventory/property rights. While the list of goods inventory/property rights is a valuable document that shows a number of the vessels of the organization and controlled the direction of the organization to rebel in the sub parts, either move or not move[1]. The existence of the complete supply list, orderly and sustainable development in all Sub Section of the organization has a function in order to:

- Uncontrollable goods / administration of property rights. 
- Registration, control and supervision of each property rights.

- The attempt to take advantage of the use of every goods/maximum property rights in waging the achievement of the intent and purpose of the organization.

- Support the implementation of the implementation of the organization

\section{B. Procurement of Goods}

Procurement of goods/services is the activities of the procurement of goods/services carried out in a self-contained and by goods/service provider.

There are several terms that used in the procurement process, including[1]:

- Budget users as the worker whose responsible for the implementation the procurement of goods/services.

- Goods/service provider, is the part of the business or individuals that provide goods/services.

- Goods are objects in various forms, which include raw materials, semi-raw material, goods/equipments specification that specified by the user of goods/services.

- Special services is divided into 3 types, namely contractor services, consulting services and other services.

\section{Data Mining}

Data Mining is a series of processes to explore the added value in the form of the information for this is not known manually from a database[2]. Information is obtained by extracting and identifing the pattern of the data that found in the database. Data mining especially used for searching the knowledge of large databases, often called Knowledge Discovery in Databases (KDD)[2].

This knowledge searching process using a various of learning techniques (machine learning) to analyze and extract. The searching process is iteratif and interactive to find the pattern or model that is invalid, new, useful, and understood. In its application, data mining requires data analysis software to find patterns and relationships of data that can be used to make the accurate predictions [2].

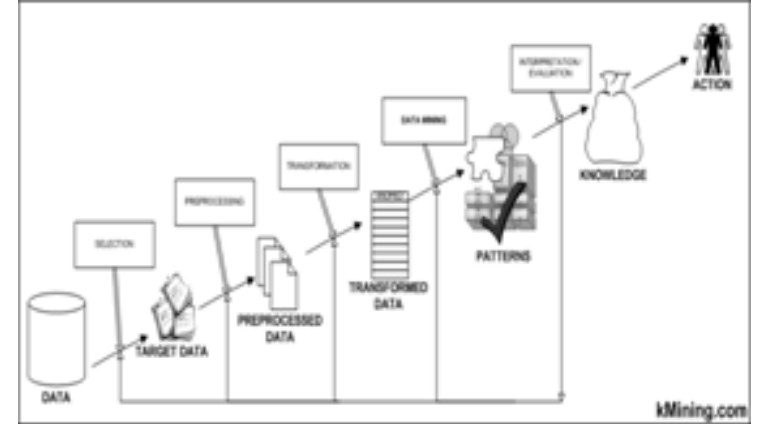

Figure 1. The Phases of The Dat a Mining

\section{Decision Trees ( Decision Tree)}

Decision tree is the tree which is in the troubleshooting analysis, about mapping troubleshooting alternatives that can be taken from the problem[3]. The tree also shows the probabilities that will affect the alternatives decision, accompanied by estimation of the final results that will be acquired when we take the alternatives [4].

For example, a decision tree can be used for management and business in the next business planning. One of the important stage is the decision making stage. Decision tree has benefits as follows :

- Useful in exploring the data, so that the hidden data can be processed and developed again.

- For the breakdown complex decision-making processes become more simple, so the decision makers will be more interpret the solution of problems.

- Can be made tool decision making deals.

- Change the complex decision became more simple, specifically, and easy.

\section{E. The CARTS Algorithm}

CARTS (Classifcation and Regression Tree) is one of the methods or the algorithm from one of the data exploration techniques namely decision tree technique[5]. CARTS is developed to classification analysis on exchangeable good response nominal, ordinal or continuous. CARTS produce a classification tree if the response is exchangeable and produce regression tree if the response exchangeable continuously. This method is developed by Leo Breiman, Jerome H. Friedman, Richard A. Olshen and Charles J. Stone around 1980[5].

The value of the smallest error rate on the classification tree will create tree that will be used to estimate the response. The principle method of this classification tree is separating all the observations into two clusters and separating the clusters into next two clusters, until obtained the number of minimum observations on each next cluster.

\section{F. The object-oriented methodology}


The object-oriented methodology is a software development strategy to organise the application as a collection of objects that contains data and operations imposed. Object-oriented methods based on the implementation of the principles of the management of complexity[6]. Object-oriented methods include a series of activities of object-oriented analysis, design objectoriented programming, object-oriented, and testing of object-oriented.

The applications developed at this time is very varied (business applications, real-time, utility, etc.) with different platforms, thus causing demand development methodology that can accommodate to all types of application[7]. Methodology of objectoriented benefit increase productivity, accelerate in development, easy maintenance of consistency, improve the quality of the software.

\section{G. UML ( Unified Modeling Language)}

UML ( Unified Modeling Language ) is a visual modeling method to design and or make software object-oriented. Because UML is a visual language for the modeling language of objectoriented, then all the elements and diagrams based on object oriented paradigm. In addition to the UML is a language of visual programming technique, can also directly connected to the various languages programming technique or even connected directly into an object-oriented database [8].

\section{H. Web Pages}

Web Page is a facility of Web Hypertext to display the data as text, figs, animation and other mu ltimed ia data that are related to each other.

\section{RESEA RCH METHOD}

\section{A. Data Collection Method}

The first step in this research is collecting the data and information related to the system of stock in the company warehouse.

Collecting the data has been done as follows:

a. Library Study, at this stage is done troubleshooting data and the collection of the information used to design the inventory information system web-based goods on the company warehouse.

b. The observation

This technique is to get the primary data with how to observe directly against the object of the data examined.

\section{B. System Development Method}

The development of the inventory system is using object-oriented method with UML, includes the six main stage, namely planning, object-oriented analysis, design object-oriented includes the functional design of the database and the implementation of the object-oriented.

\section{RESULT AND DISCUSSION}

\section{A. Planning ( Planning)}

In this stage, researchers determined the scope of web-based inventory system, procurement and supplies. The scope of procurement consists of 5 (five) functions, namely inventory, demand for goods, procurement, acceptance of goods and reports from the inventory data and procurement of goods

\section{B. Analysis (Analysis)}

At this stage, researchers analyzed the current system and determined the needs that would be proposed in in the design of applications.

- Explanation of the current system

Based on the observation result of several companies warehousing, found that during these preparation process activities of goods not accommodate yet the needs of the recording and reporting of stock.

- The proposed System Analys is

Based on these problems, can be defined the needs is preparation of procurement of goods to each integrated between all parts .

1) Analysis of the Data Processing Method of Goods. For data processing techniques goods, using data mining techniques. Now for the implementation of data mining in this system is as follows :

a) To view information of any part which often do request goods (viewed from the daily report/monthly demand for goods).

b) To view information of which part that have inventory stocking most.

c) To view the information of goods which are the most frequently in-request and most frequently consumed her preparation.

The following is the implementation of the method decision tree on the Inventory Information System Web Based Goods:

1) Any part that often do the request of goods.

The author uses the example of ink toner printer as goods and durable goods data based on monthly data

The results concluded that the marketing is the most extravagant in using ink toner printer. Due to print sales report, print design brochures, print brochures so, print Fig design for advertisement, etc. for product marketing company. 


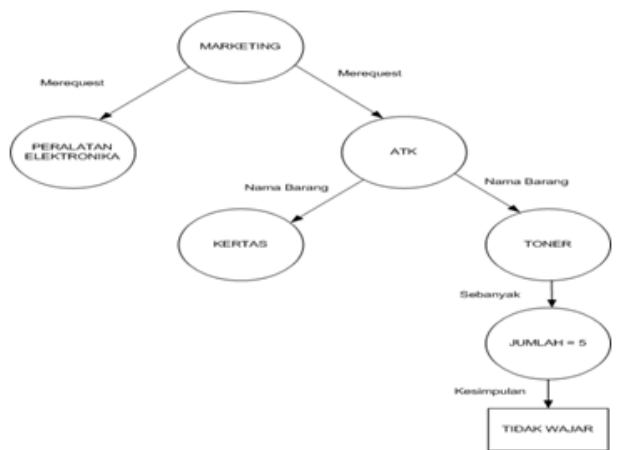

Figure 2. Decision Tree to Demand for Goods in The Marketing

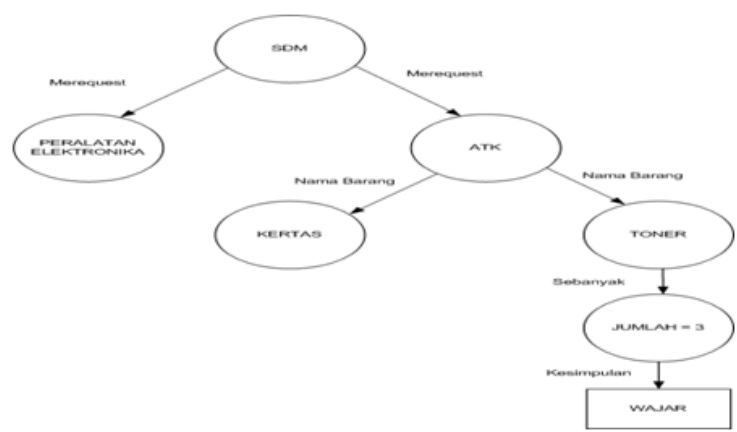

Figure 3. Decision Tree to Demand for Goods in The Human Resources

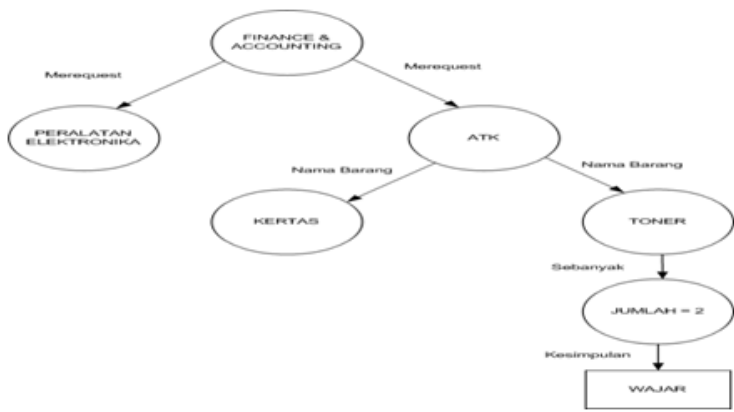

Figure 4. Decision Tree to Demand for Goods at The Finance

2) Any part that have inventory stocking most.

To inventory data goods author take samples monthly inventory data.

The results concluded that the marketing is the part that has the most equipment inventory. The marketing is divided into 2 (two) functions, namely Administration function and the Sales function. The duty of administration are inputting and processing the sales data and provide the report to the affair and the Board of Directors. While the duty of sales is sell the products to the domestic market as well as abroad. The authors suggest that the sales function not need to have a PC (Personal Computer) because their work spent many time outside the office. Other way to the administration that doing many activities in the office. the Marketing still less effective in using existing PC.

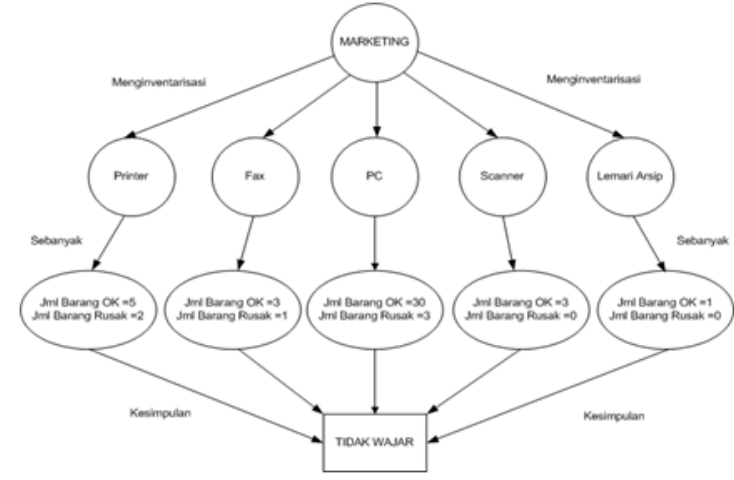

Figure 5. Decision Tree to Invent ory Stocking at The Marketing

3) What goods are most often in-request and most frequently consumed.

For data of goods author take samples request monthly goods.

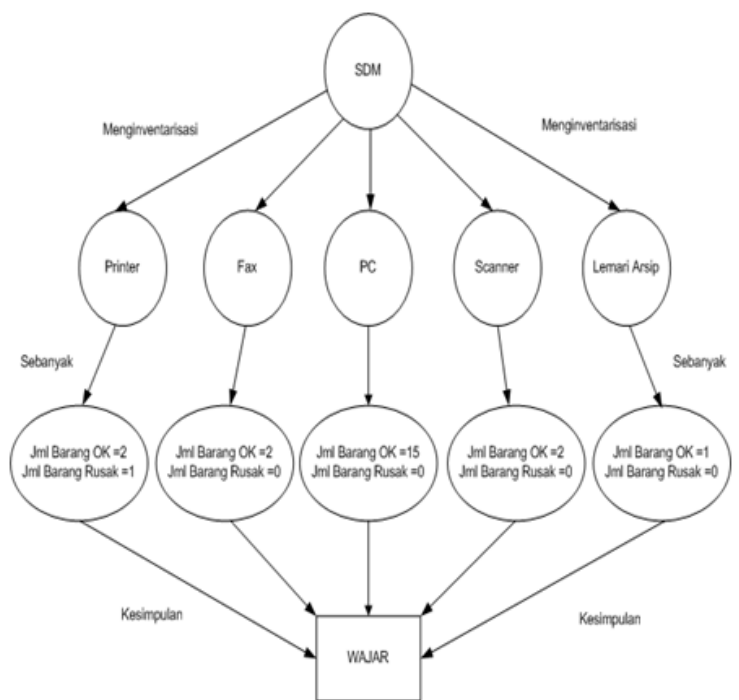

Figure 6 Decision Treeto Inventory Stocking in Part of Human Resources

The results concludes that for STATIONARY equip ment with the type of ink toner HP Laserjet 1606DN is the type of goods that mostrequest and most quickly finished his preparation. Due to the necessity to print product design design company, print design brochures, print the letters of introduction, print the letter out and print the design of the image for advertising. 


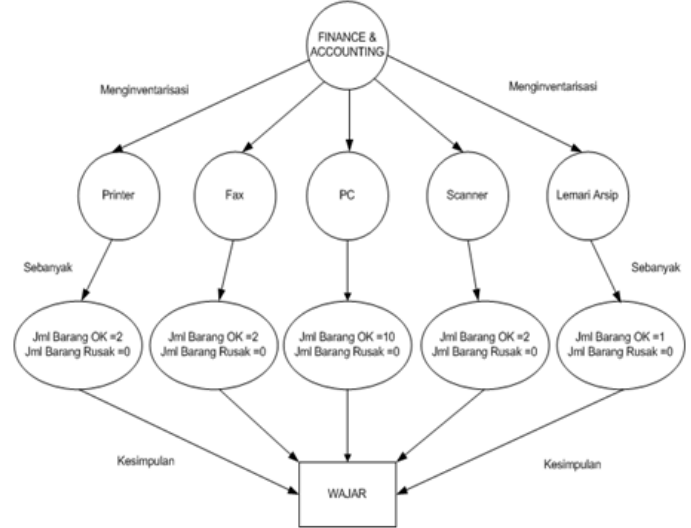

Figure 7. Decision Tree to Invent ory Stocking at The Finance

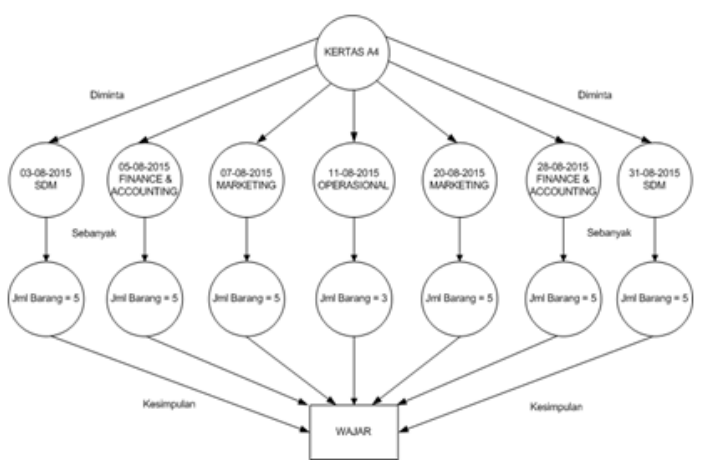

Figure 8. Decision Tree Seen From Per Type of Goods

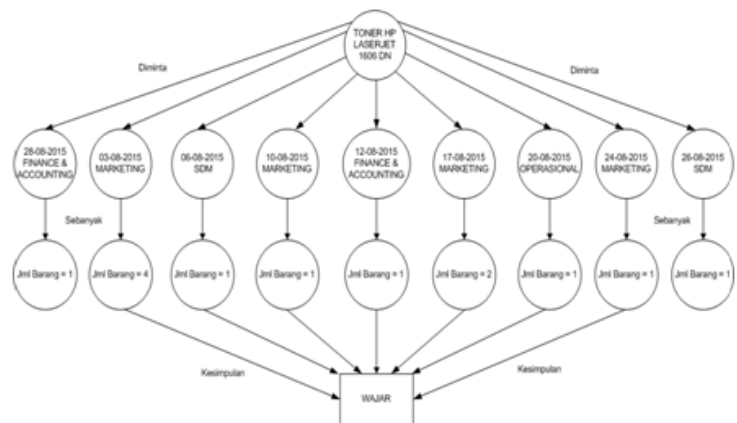

Figure 9. Decision Tree Seen From Per Type of Goods

The steps of the process of data mining processing method for data processing of goods is as follows :

a) Data Selection

Grouping of goods data, such as hygiene STATIONARY, electronic equipment, and equipment non-electronics.

b) Data cleaning

Check the data items are grouped, duplication of data, inconsistency of data such as the one in the data division of goods should be entered into the category of STATIONARY equipment, but into electronic equipment and repair the errors on the data such as, error print request evidence of goods request vessels BUYING MATERIALS, but on the evidence of the printed report request electronic equip ment.

c) The transformation of data

To change the form of the data item that will be ready to mine out. Mine out means done excavations related information from some types of goods data.

d) Data Mining

After data transformation of goods and the goods data ready to be excavated. As kits, STATIONARY divided into several kinds of : paper, ink printer, bindex, staples, etc).

e) The interpretation of Evaluation

The last stage of the data mining that will produce an information or knowledge for the user. For example, before performing the request of goods, user can view the list of the inventory that is available in the system. When the inventory sufficient, then the user can perform the request of goods if the inventory has reached the limit, the user cannot perform the request of goods. To request new goods that previously did not exist in the system, user can apply for the procurement in the system.

- The proposed System Description

The proposal to build an application Information System of Web-based Procurement preparation is required analysis needs are as follow:

a) Inventory stocking

Every part must register inventory has no, which would later become a report to the logistics.

b) Demand for Goods

Every goods that required will request to logistics staff with full filling the demand online form at Inventory Information System application web-based procurement.

c) Procurement of Goods

The logistics staff will full filling the new goods to the leaders and asking the approval for it.

d) The acceptance of Goods

The logistics staff does an assessment of the transaction process and the delivery of the needed goods.

e) The Report

The logistics staff provides a report related to inventory activities, request and procurement.

- Mechanism of the process of acceptance of Goods

The acceptance goods in the warehouse system is the beginning process of the administration of a warehouse. Start the recording of the letter the way or purchasing order from supplier, perform the calculation of the number of incoming stock of goods from supplier (randomly), signed purchasing order from the supplier and done the handover of goods and the last is doing goods 
input into the Inventory Information System Web based goods. Fig. 10 is the mechanism of the process of acceptance of the goods from the supplier.

- Mechanism of the process of the request of Goods

The warehouse administration system has to make sure there is a process of demand for goods from user. The following is the process of request of goods is done by user:

a. User monitoring goods that want to inrequest through the inventory menu.

b. When the goods are still enough user demand for goods.

c. If the user to request the equipment, both electronics and non-electronics, then the user must perform inventory stocking.

d. If in addition, such as request equipment STATIONARY user is not required to perform inventory stocking.

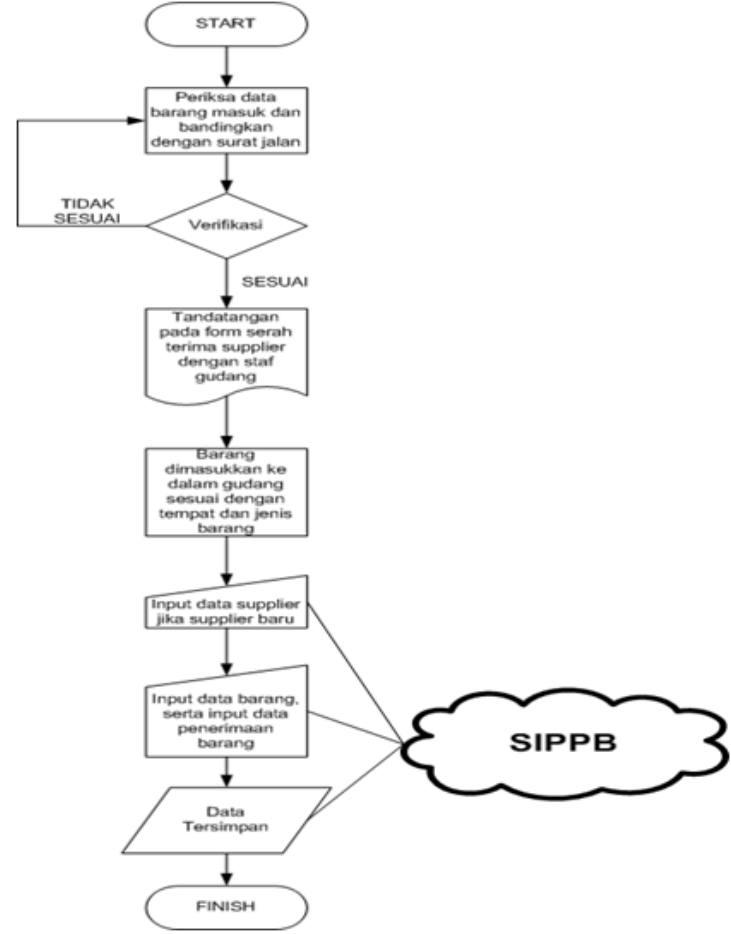

Figure 10 Mechanism of The Acceptance of Goods Online

e. User confirmation to the warehouse staff logistics section, goods was successful inrequest in the system.

f. Warehouse staff print form the handover of goods through the system and signed by user and staff of warehouse.

g. User with warehouse staff went to the warehouse to take the things that are in therequest by user.

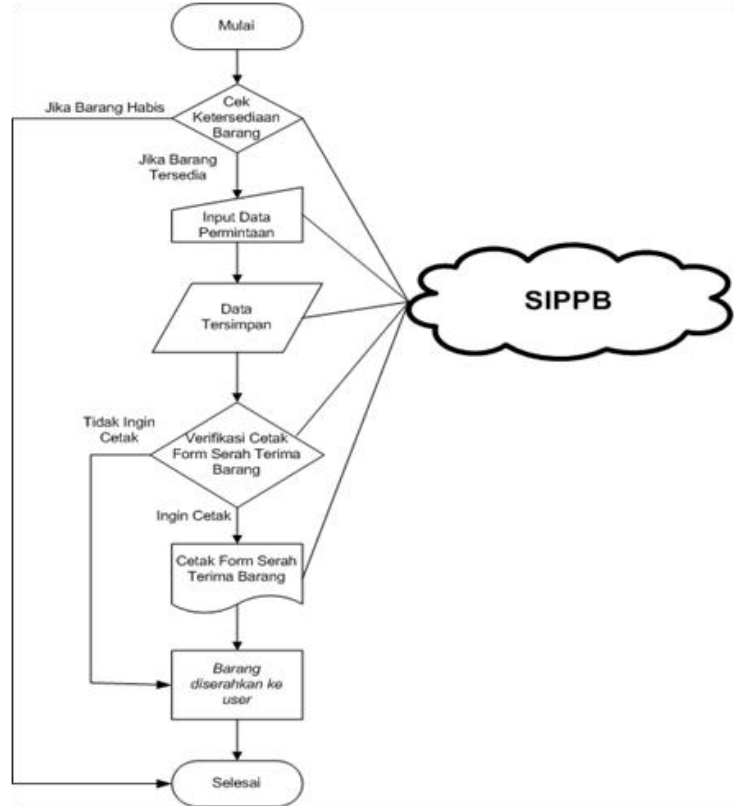

Figure 11 Request Mechanism of Goods Online

5. Mechanism for the process of procurement of goods

Procurement of Goods done if there are several types of goods that does not exist in the warehouse or goods which want to prompted timed out. Now the mechanism can be seen in the Fig 12.

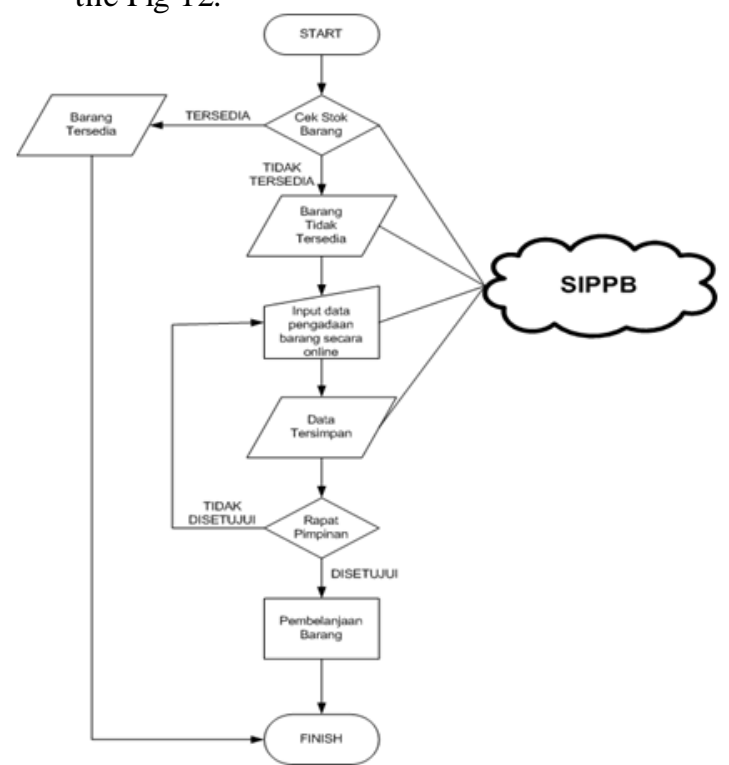

Figure 12. The Mechanism of Procurement of Goods Online

C. Design the system

At this stage the authors use UML system development methods (Unified Modeling Language), include:

- Use case diagrams

Use case diagrams on the Fig 13 shows the blue print the system oversupply of goods. 


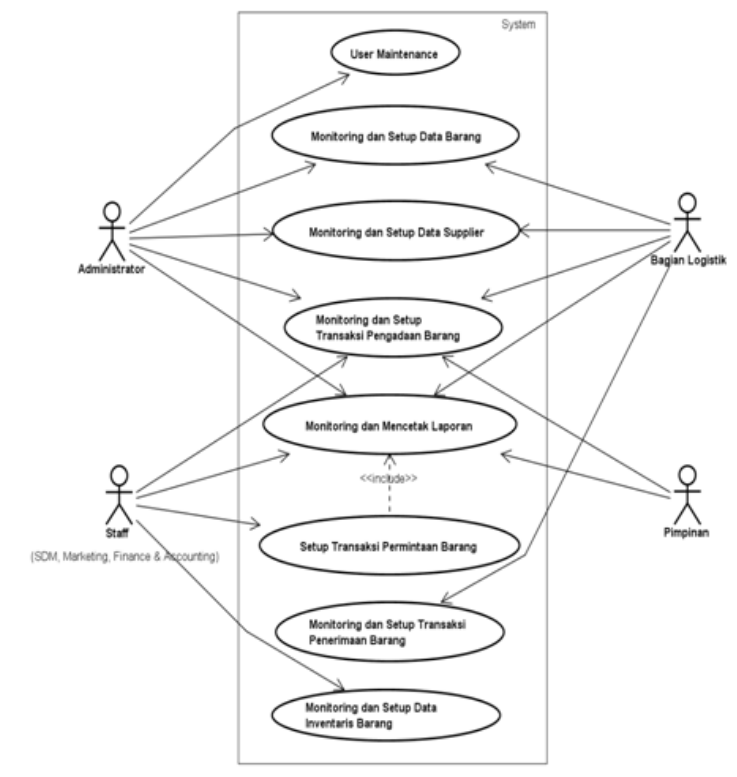

Figure 13. Use Case Diagram

\section{- Class Diagram}

Class Diagram on the Fig 14 explains the relation between the classes that are located in the Information System inventory stocking.

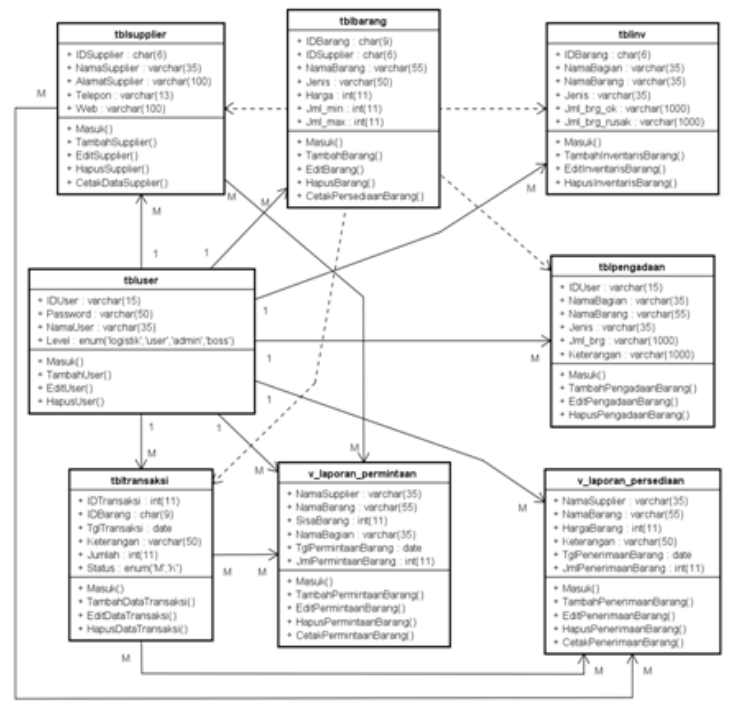

Figure 14. Class Diagram

\section{- Component Diagram}

Component Diagram (Component Diagram) is used for are modeling the physical aspects of a system inventory. On the component diagram of the Fig 15 explains that the components involved in the system.

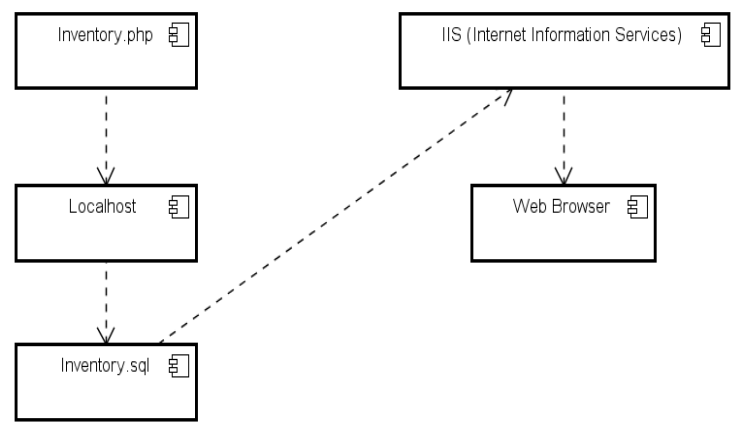

Figure 15. Component Diagram

The software that is needed to build information system inventory these items have a minimum specification as follows :

Operating system : Windows 7 Home Basic

System Design Application : AstahUML

Website Develop ment Application : PHP

Development Application Data Base: MySQL

\section{- Deployment Diagram}

Deployment diagram shows the layout of a physical system. Fig 16 is a deployment diagram of the system inventory.

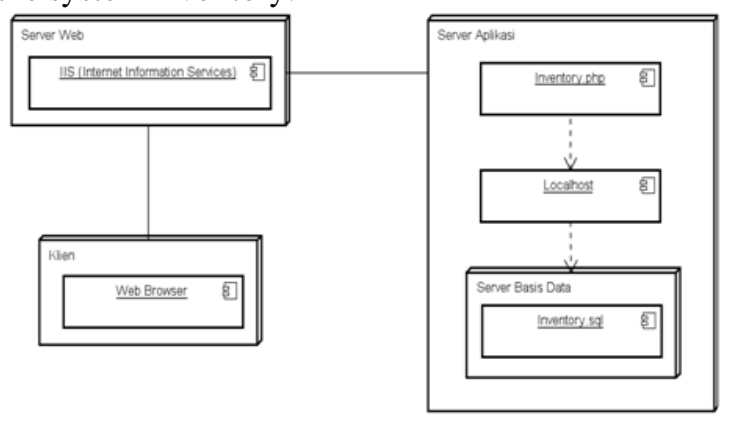

Figure 16. Deployment Diagram

Hardware requirements are needed to build information system inventory. These items have a minimu $\mathrm{m}$ specification as follow :

$\begin{array}{ll}\text { Processor } & : \text { Intel Pentium Core i3 } \\ \text { RAM } & : 4 \mathrm{~GB} \\ \text { Hardisk } & : 224 \mathrm{~GB} \\ \text { VGA } & : 1 \mathrm{~GB}\end{array}$

\section{The implementation}

Based on the system design, implementation phase is done as follows:

- For in terms of security, one in entering a password as much as 3 (three) times, then the system will auto matically block the user and are invited to contact the admin is trator.

- User Maintenance. This page has the function to perform the addition, conversion or elimination of user data. Authorization accessing only done by an admin istrator.

- Monitoring and Setup Data Items. This page function to perform monitoring and data input 
goods that have been supplied by the supplier. Accessing the authorization is only done by the administrator of the Warehouse Staff Logistics section.

- Monitoring and setup the Data Supplier. This page function to perform the addition of new data or existing data on supplier. Accessing the authorization is only done by the administrator and staff of Warehouse Logistics section.

- Monitoring and Setup Procurement of Goods. This page function to perform the procurement of new goods, if the goods on the stock of goods in the warehouse does not exist. Accessing the authorization can be done by all users ( user).

- Monitoring and print the report. Sub menu on the menu of the report can be used to print the report or only doing monitoring only. The report is all the transaction data in the Information System inventory stocking. Accessing the authorization can be done by all users ( user ).

Now for the mechanis ms of data mining on this system can be seen and downloaded from the report per transaction type. The transaction is first, to know any part that have inventory stocking most. Second, to know any part that often make the request of goods (can be seen from the daily report/monthly discounted rates demand for goods). Third, to know what goods that most-request and most frequently consumed her preparation (can be seen from the daily report/monthly discounted rates demand for goods). The explanation is as follows :

1. Know any part that have inventory stocking most

To know any part that have inventory stocking most, can be seen in the report menu and then select the sub menu inventory stocking. After appears the report and data can be downloaded by clicking on the Export To Excel. Then done sorting data per each section and done the recapitulation and evaluation.

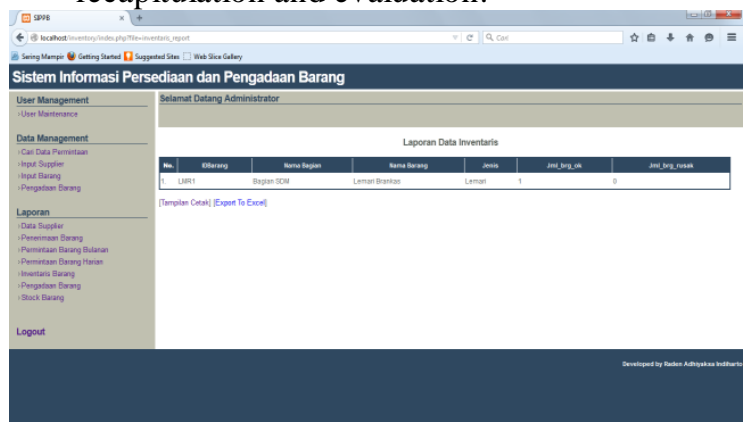

Figure 17. Goods Inventory Report Page

2. Know any part that often make the request of goods

To know every part that often do the request of goods can be seen on the report menu and then select the sub menu daily goods request or demand for goods monthly. Depending on the data that you want to taken, good based on demand transactions daily and monthly. If you want to see the report, enter the period discounted rates enjoying a good daily transaction or monthly and a description.

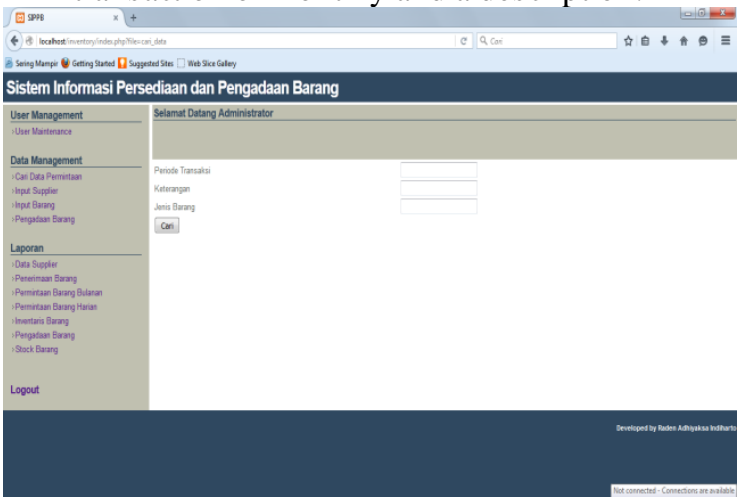

Figure 18. Search Page Request Transaction Based on The Period of The Transaction Description or Type of Goods

On this page, users are required to enter the transaction period and a description of the request that you want to get good is based on the name of the part or the requested goods. After inserted, click Search, then the report will be directly appears with itself.

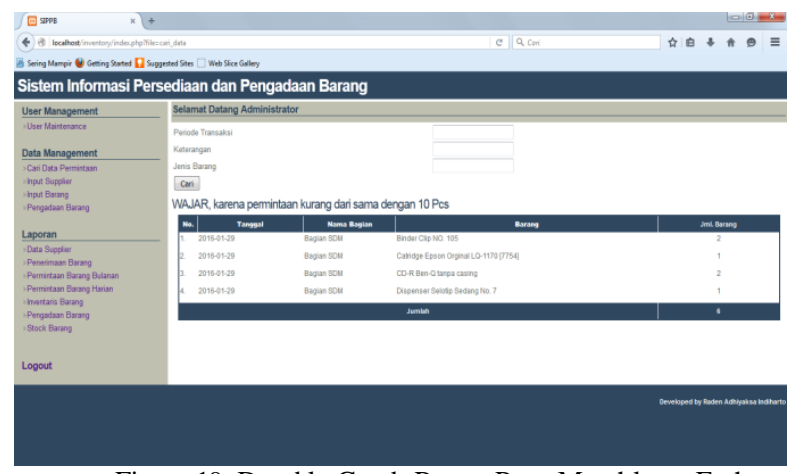

Figure 19. Durable Goods Report Page Monthly on Each Section

After appears the report, Warehouse Staff Logistics Section can know whether "normal" or "fair" section in the conduct of the request of goods on a monthly period.

3. Know what goods are most often in-request To know the type of goods what are the most frequently asked, can be seen on the report demand for goods both daily and monthly. The methods are the same with the steps to know any part of the most complete the request of goods, only the data inputed based on the requested goods. Fig 20 indicates the type of goods that most requested. 


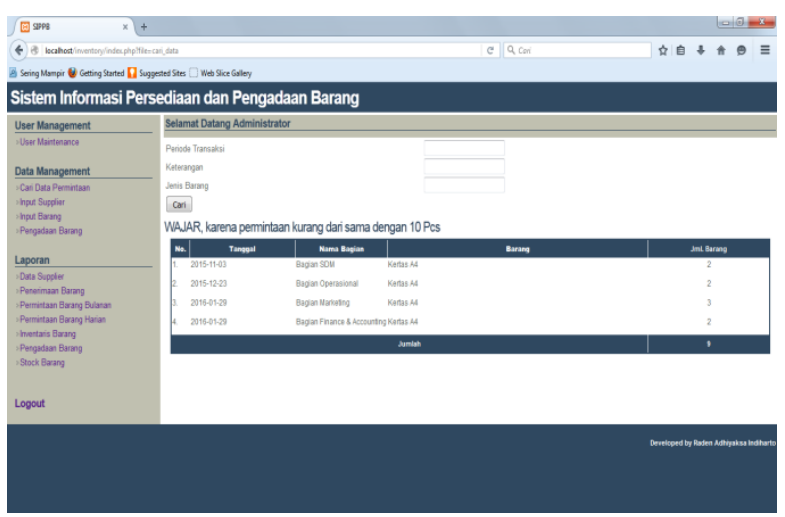

Figure 20. The Page Request Report Monthly Goods Based on The Requested Goods

- Setup Discounted Rates demand for Goods. This page work to do transaction demand for goods. Authorization accessing this page can only be done by the Staff of the section. When the goods have reached the limit and the staff could not do request. This happens because it has been programd by the author so that the preparation of goods in the warehouse is not necessarily low total, but has a number of limit which will later be used as a reference for the Warehouse Staff Logistics section to perform the procurement of goods return.

- Monitoring and Setup Transaction receipt of Goods. This page is a form to do transaction receipt of goods from the supplier. So after doing the handover of goods between the Warehouse Staff Logistics Section with Supplier, then the goods inputed into the system. Authorization accessing this page can only be done by Gudan Staff Logistics section.

- Monitoring and Setup Inventory Data Items. After making the request of goods in the form of demand for goods, Staff Part must perform inventory stocking if the requested goods is the electronic equipment/non-electronics and not the attachment STATIONARY. Accessing the authorization can only be done by the Staff of the section.

\section{V.CONCLUSION}

Based on the results of research the author obtain from analysis process, design and the construction of the system, the author gives the conclusion as follows :

1. This system has the advantage, i.e. can perform data mining process that will be useful for evaluating the management in decision making.

2. From the results of the test and implementation, the authors conclude this system has features as follows : a. Create the access rights for the user so that only users who have been counted in the data base that can be entered into the system.

b. This system makes it easier to pengaksesannya because web based and can be accessed from anywhere and anytime.

c. Makes it easier to count the number of goods and assets on when done stock opname from items that have been there in the warehouse and inventory assessment of goods owned by each section.

d. The process of the presentation of the report quickly and accurately when needed.

e. From the results of the test of this system can be operated with good.

\section{REFERENCES}

[1] Irfan Hilmi Hamdani; Wakhid Ahmad Jauhari; Alifah Khairina, 2015. A supply chain inventory model with imperfect quality and stochastic demand. Proceedings of the Joint International Conference on Electric Vehicular Technology and Industrial, Mechanical, Electrical and Chemical Engineering (ICEVT \& IMECE), Pages: 53-57.

[2] Santosa, Budi . 2007 . Dat a Mining: Engineering Data usage for business needs. Graha Knowledge: Yogyakarta.

[3] Satya Samyukta Kambhampati; Vishal Singh; M. Sabarimalai Manikandan; Barathram Ramkumar, 2015. Unified framework for triaxial accelerometer-based fall event detection and classification using cumulants and hierarchical decision tree classifier. Healthcare Technology Letters, Volume: 2, Issue: 4.

[4] Anaël Bonneton; Daniel Migault; Stephane Senecal; Nizar Kheir, 2015. DGA Bot Detection with Time Series Decision Trees. 4th International Workshop on Building Analysis Datasets and Gathering Experience Returns for Security (BADGERS), Pages: $42-53$.

[5] Asry Faidhul Ashaari Pinem; Erwin Budi Setiawan, 2015. Implementation of classification and regression Tree (CART) and fuzzy logic algorithm for intrusion detection system. 3rd International Conference on Information and Communication Technology (ICoICT), Pages: 266 - 271.

[6] Malin Källén; Sverker Holmgren; Ebba póra Hvannberg, 2014. Impact of Code Refactoring Using Object-Oriented Methodology on a Scientific Computing Application. IEEE 14th International Working Conference on Source Code Analysis and Manipulation. Pages: $125-134$.

[7] Nur W. Rahayu; Sri Hartati, 2012. CAI of flowchart (CAIFlow) development using object-oriented methodology. International Conference on Computer \& Information Science (ICCIS), Volume: 2 Pages: $843-847$.

[8] Tohari, Hamim . 2 No. 14 . The analysis and design of Information Systems through the UML approach. Andi : Yogyakarta. 